\title{
Libertinos y spinozistas. Dos categorías que atraviesan el siglo XVII
}

\author{
Libertines and Spinozists. \\ Two Categories that Penetrate the 17th century.
}

PEDRO LOMBA*

\begin{abstract}
Resumen: En el presente estudio se intenta determinar el sentido y el alcance de dos términos frente a los cuales se ha construido la filosofía moderna triunfante en su época. El análisis muestra que dicha filosofía expresa a su modo ciertas posiciones teológicas y políticas, y que con aquellos términos - «libertinismo»y «spinozismo»- es designado un enemigo común para ambas disciplinas que, con el paso de los siglos, terminará por imponerse como corriente filosófica fundamental de una Modernidad que ha combatido por excluirlo de su horizonte.
\end{abstract}

Palabras clave: Nueva filosofía, libertinismo, libertad, ateísmo, apologética católica.

\begin{abstract}
The aim of this paper is to analyse the sense and the scope of two terms against which the dominant Modern Philosophy has been constructed. The analysis shows that this Philosophy expresses in its own way some Theological and Political positions, and that those terms -libertinisme and «Spinozism»- serve to name a common enemy to both subjects. Almost two centuries later, it will be recognised under these categories a fundamental current of thought that has enormously contributed to the intellectual construction of a period of unmerciful hostility against them. Keywords: New Philosophy, Libertinisme, freedom, Atheism, Catholic apologetics.
\end{abstract}

No cabe duda de que los términos «libertino» $\mathrm{y}$ «spinozista» fueron forjados como dos vituperios con los que descalificar sin demasiadas contemplaciones determinadas posturas prácticas, pero también teóricas, consideradas como de todo punto indeseables. Para estudiar la genealogía, significación y continuidad conceptual de ambas categorías, debemos situarnos en el horizonte de la Francia del siglo XVII y partir de la constatación de que sus años veinte fueron decisivos para el destino intelectual de Europa ${ }^{1}$.

Fecha de recepción: 01/03/2015. Fecha de aceptación: 01/06/2015.

* El presente artículo ha sido escrito como parte del Proyecto de Investigación Biblioteca Saavedra Fajardo de Pensamiento Político Hispánico: Ideas que cruzan el Atlántico. La creación del espacio intelectual hispanoamericano (FFI2012 - 32611) del Ministerio de Economía y Competitividad. Pedro Lomba es profesor en la Universidad Complutense de Madrid. Contacto: pedro.lomba@filos.ucm.es

1 Un estudio más amplio de dicha genealogía y continuidad es el que he ensayado en P. Lomba, Márgenes de la modernidad. Libertinismo y filosofía en el siglo XVII, Madrid, Escolar y Mayo, 2014. 
Las condiciones de la vida política y social francesa son, en efecto, particularmente llamativas durante un decenio en el que se gesta la filosofía «clásica» más emblemática: el gran sistema cartesiano. La forma teológico-política de este período parecería propiciar, al menos en la teoría, un ambiente de pacífica convivencia, anómalo en el resto del continente. El Edicto de Nantes, firmado por Enrique IV en 1598 para poner fin a casi medio siglo de guerras civiles de religión, está aún en vigor, lo que significa que el catolicismo y el protestantismo calvinista, tan expandido por el país, son igualmente oficiales. A primera vista, cierta libertad religiosa y, por tanto, de pensamiento, parece gozar de alguna garantía oficial...

Sin embargo, lo que da su forma más peculiar a estos años es una acometida feroz del catolicismo para ganar una primacía religiosa, política e intelectual totales. El siglo XVI ha vivido la brutalidad de las guerras civiles de religión entre católicos y hugonotes, y el Edicto no ha sido sino una suerte de solución provisional para poner fin a los desastres producidos por unos enfrentamientos especialmente sanguinarios. Lo que se percibe ahora es que el desgaste moral provocado por las guerras ha desencadenado en la sociedad francesa una explosión de impiedad e incredulidad que amenaza con disolver todo atisbo de orden moral y religioso. Al menos eso es lo que afirman, con la máxima insistencia, dos de los apologistas católicos más activos durante esta década: el jesuita François Garasse ${ }^{2}$ y el mínimo Marin Mersenne ${ }^{3}$. Ambos, entre 1623 y 1625, publican un conjunto de escritos polémicos que dan la medida perfecta de la gran tensión moral, política y teológica del momento. En ellos restalla, como un látigo, la violencia que acompaña a todo esfuerzo por instaurar una hegemonía que se quiere definitiva y total. Es en esos textos, y sólo en ellos, donde se forja una categoría que va a recorrer el siglo y que va a movilizar las energías de muchos de sus protagonistas.

Esta ofensiva católica se manifiesta como un encarnizado ataque contra un conjunto de movimientos intelectuales que, a pesar de remitir a posiciones teóricas distintas, rápidamente son subsumidos bajo el impreciso y problemático término de «libertinos». Deístas, escépticos, nuevos epicúreos o ateístas de todo tipo movilizan en su contra las fuerzas católicas más enérgicas. Sin embargo, lo realmente significativo es que éstas parten de una convicción crucial: la tormenta de impiedad que azota al país debe ser relacionada muy esencialmente

2 En tres escritos fundamentales de los que nos ocupamos a continuación: La Doctrine curieuse des Beaux esprits de ce temps, ou pretendus tels (París, S. Chappelet, 1623, in-4 $4^{\circ}, 986$ fols.), su Apologie du père François Garassus, de la Compagnie de Jesus, pour son Livre contre les Atheistes \& Libertins de nostre siècle. Et response aux Censures et Calomnies de l'Autheur Anonyme (París, S. Chappelet, 1624, in-12, 360 fols.) y el Nouveau Jugement de ce qui a esté dict et escrit pour \& contre le livre de la Doctrine curieuse des beaux esprits de ce temps, \& c., París, Jacques Quesnel, 1625.

3 En tres obras en las que conjunta su esfuerzo contra el ateísmo y la impiedad: Quastiones celeberrima in Genesim, cum accurata textus explicatione (París, S. Cramoisy, 1623, in-folio), L'impieté des Deistes, Athees et Libertins de ce temps, combatuë et renversee de point en point par raisons tirees de la Philosophie et de la Theologie. Ensemble la refutation du Poëme des Deistes (París, P. Bilaine, 1624, 2 vols., in- $8^{\circ}$, 834 y 506 fols.), y La Verité des Sciences. Contre les Septiques [sic] ou Pyrrhoniens (París, T. du Bray, 1625, in- $8^{\circ}, 16$ fols. + 1008 pp.). A los nombres de Garasse y Mersenne se deben sumar los del padre Caussin (con su escrito La Cour Saincte, ou l'Institution chrestienne des Grands, Ruán, David Ferrand, 1624, in-8 ${ }^{\circ}, 12+646$ pp.) y Jean-Louis Guez de Balzac, quien se muestra muy activo en su correspondencia: Lettres, París, T. du Bray, 1624, in- $8^{\circ}$, 609 pp. Recuérdese que en 1657 Clerselier, el editor y traductor de Descartes, publica como carta remitida a un corresponsal anónimo un texto del filósofo en el que alaba las Lettres de Balzac: la Censura quarumdam Epistolarum Domini Balzacij, escrito en 1628 (AT, I, 7 - 11). 
con la moderna herejía que tantos sufrimientos ha provocado en el pasado reciente. La Reforma protestante es denunciada sistemáticamente como la responsable última de la inmoralidad y la irreligiosidad reinantes, como la levadura que ha dado su monstruoso volumen al escepticismo, al deísmo, al epicureísmo, al ateísmo de estos tiempos nuevos. El historiador de las ideas que se asoma a los textos apologéticos de estos años veinte, goza del raro privilegio de asistir a una confrontación en la que se muestra con una claridad insólita que las polémicas teológico-políticas y la progresiva definición y transformación de los conceptos están estrechamente ligadas. La historia de ambos términos de la relación -la historia de dicha polémica y la genealogía del concepto de libertinismo- es indisociable.

Por ello, el historiador de las ideas no puede dejar de plantearse las siguientes preguntas: ¿y si el término «libertino» no fuese sino una invención combativamente católica para legitimar el blindaje del espacio político e intelectual del que pretende adueñarse? ¿Y si fuese una categoría forjada para combatir la teología protestante, para consolidar la idea de que el brote de impiedad que amenaza con la destrucción de Francia se debe principalmente a la difusión de la Reforma?

El estudio de la formación de dicho concepto debe arrancar de una constatación fundamental: su forma definitiva resulta de las polémicas -centrales para la teología y también para la reflexión filosófica de los siglos XVI y XVII- en que se miden posiciones enfrentadas a propósito de las ideas de libertad y liberación. Y sabemos que este período es el de una inmensa guerra a muerte de cristianos contra cristianos, la cual se perpetúa, alimentándose de nuevas formas y estrategias, durante un tramo de tiempo bastante prolongado. Calvinistas contra espirituales desde mediados del XVI, católicos contra reformados en la primera mitad del XVII, jesuitas contra jansenistas ${ }^{4}$ un poco más tarde... El cristianismo se presenta como un verdadero campo de batalla... Pero lo decisivo aquí es que estas luchas son también -son sobre todo- esenciales para comprender la forma que adoptará la metafísica más sistemática del siglo XVII; el resultado de esta guerra entre cristianos será el triunfo, la apoteosis, de una representación muy determinada de Dios, del hombre y de la potencia de ambos...

El espacio intelectual moderno, más allá de los textos o de las teorías particulares que lo ocupan dotándolo de un contenido concreto, se construye en virtud de una idea -la de libertad- que define y organiza una serie de conceptos -voluntad o libre albedrío, sustancialidad del sujeto de la acción, bien y mal como valores objetivos- cuya mera puesta en cuestión acarrea la expulsión inmediata a su exterior ${ }^{5}$. Es decir, a una zona ciega, invisible, de su legado cultural. Todo sistema que organice y defina estos conceptos proponiendo una revisión profunda o un rechazo tajante de aquella idea de libertad, será literalmente considerado como fruto de la locura, de la perversión, de la maldad. Quedará automáticamente confinado en los márgenes de la cultura europea, desterrado del canon de la filosofía por un período de tiempo que variará en función de las transformaciones que experimenten los intereses políticos, teológicos o incluso económicos que sostienen a dicha cultura. La asunción de cierta

4 Aunque el jansenismo, y sus polémicas con los jesuitas, cae fuera de los límites de este trabajo, no me resisto a remitir al lector al espectacular libro de José Jiménez Lozano, Retratos y naturalezas muertas, Madrid, Trotta, 2000, así como a los de Gabriel Albiac, Sumisiones voluntarias. La invención del sujeto político, Madrid, Tecnos, 2011, pp. 153 - 223, y Blaise Pascal: La máquina de buscar a Dios, Madrid, Tecnos, 2014, pp. 17 - 63.

5 Sigo aquí a Pierre-François Moreau, Spinoza, París, Seuil, 1975, pp. 21 - 28. 
idea de la libertad de la voluntad - la afirmación de una voluntad cuyas determinaciones no proceden, en principio, de nada exterior a ella misma- será lo que proporcione presencia histórica, actualidad filosófica en el XVII, a la reflexión sobre la naturaleza humana -y divina-, y sobre la moral. La constitución de la Modernidad, ciertamente, no habría sido posible sin el esencial concurso de la teología cristiana y el de sus fratricidas disputas.

Es fundamental, así pues, tratar de comprender la esencia del concepto de libertinismo, su verdadero significado, en los solos textos y las solas polémicas en que realmente se construye. Únicamente tras esta ineludible tarea podremos decir algo acerca de la mutación que sufrirá ya en el último tercio del siglo, adoptando el nombre y poniéndose bajo los estandartes de uno de los más acérrimos y reflexivos críticos del filósofo cuya metafísica consolida, con una potencia inaudita, este espacio intelectual que exige a toda doctrina, como carta de naturaleza para poder asentarse en él, la asunción de aquella idea de la libertad y de los conceptos vinculados con ella. El filósofo al que me refiero en tanto que maestro cuyo sistema da solidez a este espacio, es Descartes. Y Spinoza el crítico quizás mayor de su metafísica. El nombre que adoptará a finales de siglo algo extremadamente similar al «libertinismo», será el de «spinozismo». El desplazamiento nominal, una vez revocado el Edicto de Nantes, correrá a cargo, precisamente, de un calvinista francés forzado al exilio en los Países Bajos: Pierre Bayle.

Así pues, ¿quién es exactamente el libertino en los textos en que se forja el concepto? Tal y como se construye en los escritos más combativos de la apologética cristiana de los siglos XVI y comienzos del XVII, designa principalmente a todo autor, a toda teoría, que niega una idea de la libertad de la voluntad -y los conceptos vinculados a ella: albedrío, responsabilidad moral, trascendencia divina, objetividad de las categorías de bien y mal...- en cuya aceptación se fundamenta buena parte de los dogmas más esenciales del cristianismo. También el escepticismo es considerado como una forma eminente de libertinismo. Pero en un sentido muy preciso: sólo en la medida en que desemboca, o se hace sospechoso de desembocar, en la negación de la verdad del cristianismo o de alguno de sus dogmas fundamentales, pues por sí solo no pone en peligro la afirmación del libre albedrío. Al contrario, sin ella no sería posible entender, por ejemplo, su argumentario sobre la suspensión del juicio. Importa, además, no olvidar que, en algunos momentos decisivos de su historia, el cristiano se ha revestido con las galas del escéptico. Mas nunca un cristiano ha podido comprender, o aceptar sin abandonar automáticamente su fe, lo que los historiadores de la filosofía llaman necesitarismo o naturalismo inmanentista. Con los textos más emblemáticos de la apologética cristiana de este período en la mano, es esto, muy precisamente, lo que se significa cuando se agita el espantajo del libertinismo... Veámoslo leyendo con algún detalle la apologética católica de estos años.

En todo escrito, sea de la índole que sea, hay siempre algún pasaje en el que se condensa el sentido profundo del programa que despliega. En el texto en que Mersenne emprende la refutación, precisamente, de la doctrina escéptica, detiene por un momento el curso del diálogo que finge entre el escéptico y el filósofo cristiano para hacer una importante reflexión sobre la labor que ha desarrollado en su anterior obra apologética, L'Impiété des Déistes. El fragmento a que aludo posee la importancia de una declaración de principios; en él se ofrece una definición de la esencia del libertinismo:

Es preciso [...] evitar otro error de estos malvados libertinos que se esfuerzan en persuadir a quienes no han estudiado y se dejan arrastrar por la primera opinión que 
favorece sus depravadas costumbres: que no hay ni bien ni mal en este mundo, y que las acciones que nosotros llamamos malas, o buenas, no son tales más que en la imaginación de aquellos que las creen buenas o malas, y que todas las cosas son indiferentes, lo cual es muy falso y contrario a todo tipo de razón. Es por esto por lo que he combatido este error en mi libro contra los deístas ${ }^{6}$.

Libertino, en la conciencia católica, es, sobre todo, quien niega el factum de la responsabilidad moral última de los hombres y, con ello, la libertad de la voluntad. El enemigo teórico de la apologética que queda sustanciado bajo la categoría de libertinismo es, de manera eminente, toda forma de necesitarismo.

François Garasse, por su parte, ha percibido el corazón del problema con la hosquedad teórica habitual en sus escritos. Si por algo se define el libertino, afirma constantemente el jesuita en La Doctrine curieuse, es por su negación de la libertad de la voluntad individual, verdadero fundamento de su presunta entrega, sin escrúpulos de conciencia, al desenfreno y la sensualidad más brutales. Garasse evita a toda costa entrar en una refriega puramente filosófica; se limita a sostener obstinadamente que la esencia de la libertad se cumple en la «simple» creencia en todo lo que la Iglesia propone ${ }^{7}$, afirmando con mucha rotundidad que la eficacia del combate contra la impiedad libertina está en la inequívoca asunción de la libertad del albedrío humano. Es en ella, en definitiva, donde ha quedado sellada la verdadera semejanza del hombre con Dios:

[...] Dios creó al hombre con una libertad originaria, y es en esto en lo que los intérpretes estiman que yace la semejanza que tenemos con Dios, cuando éste dijo: Faciamus hominem ad imaginem et similitudinem nostram. Pues los más hábiles escritores que han trabajado sobre el Génesis consideran, con san Damasceno, que no se puede buenamente salvar o verificar esta semejanza a no ser que la pongamos en la libertad con que nuestro espíritu está ornado, de suerte que no hay violencia ni fuerza en el mundo que la pueda contravenir ${ }^{8}$.

El hombre, pues, es semejante a Dios por constituir una excepción respecto del resto de la creación: no hay «violencia ni fuerza» que pueda doblegar su voluntad. Es decir, nada que no sea ella misma pueda determinarla absolutamente. Esto es lo que significa que la libertad sea «originaria», que sea la esencia que particulariza a los hombres en tanto que criaturas semejantes a su creador.

Zanjado así el problema, el jesuita, en el libro siguiente de su escrito, se atreverá a abordar la cuestión del destino y la predestinación, en la que percibe el verdadero punto de encuentro entre el libertino y el hugonote. A Garasse le interesa sobremanera señalar

6 La Vérité des Sciences, II, 9, fols. $427-428$.

7 Cfr. ibid., fol. 210: «[...] digo, pues, que la verdadera libertad consiste en creer francamente lo que la Iglesia nos propone, sin filosofar o sofisticar sobre ello diciendo: creo en este artículo, pues me parece más conforme con la razón o con el sentido natural, pero no creo en aquel otro, pues veo en él más dificultades o contradicciones. Hacer esto es ser filósofo, no cristiano; querer saber, pero no creer. San Agustín quería que todo el mundo supiese que para él era más importante el nombre de cristiano que el título de filósofo».

8 Ibid., fol. 209. 
- o construir- este vínculo9 ${ }^{9}$ y alertar del peligro que supone un necesitarismo que niega la potencia, la autonomía del albedrío. Sostener, por ejemplo, que lo que gobierna nuestras acciones, los «movimientos de nuestra alma», es el destino, o la causalidad mecánica que rige las combinaciones de los humores de nuestro cuerpo, equivale a destruir todo fundamento para la moral, para cualquier moral. Y por eso justificará un año más tarde, en la Apologie du père François Garassus, la vehemencia de sus ataques a Théophile de Viau, alambicada encarnación del nuevo epicureísmo:

[...] propone una máxima muy epicúrea y completamente ateísta cuando dice que los temperamentos del cuerpo fuerzan los movimientos del alma, sea cual sea el discurso que opongamos a esta necesidad. Es decir, que quien posee un temperamento corporal y una complexión inclinados a la impudicia o a la embriaguez, debe ser un borracho necesariamente y un impúdico, a pesar de lo que él pueda hacer, pese a la gracia que Dios le pueda conceder, pese a la austeridad que pueda ejercer, pese a las razones con que pueda embridar sus pasiones; en suma, a pesar de los discursos que se puedan oponer a esta necesidad, la cual es una proposición extraída de la escuela de Epicuro. Y luego se me preguntará qué tengo yo contra Théophile de Viau ${ }^{10}$.

Una nueva decepción, otra, espera al lector. El jesuita se limitará, una vez más, a remitir el problema y su solución «a las Escuelas de teología» ${ }^{11}$; la tarea de un simple clérigo como él, viene a decir, se ciñe a velar por la sumisión de los fieles al magisterio de la Iglesia, y por que no se interprete libremente la Biblia ${ }^{12}$. La urgencia por consolidar la idea de que la Reforma protestante ha sido el germen de la más perniciosa de todas las impiedades, es extrema. Pero lo que queda definitivamente fijado en el espíritu del lector es la convicción de que la tesis nuclear de la nueva impiedad, la tesis que da su forma al concepto de libertinismo, es la que niega la libertad del albedrío del hombre. Esto es, la que identifica divinidad y naturaleza (o destino); la que sustituye la idea de semejanza entre hombre y Dios, por la de una inquebrantable y generalizada sujeción a las férreas leyes de la necesidad en que consiste esa divinidad natural. Extraña libertad, esa que califica al libertino...

La calidad teórica de los escritos de Marin Mersenne es muy otra. En ellos se puede apreciar una cierta tendencia a la discusión de las ideas ausente de las diatribas de Garasse, aunque los principios sean los mismos para ambos, y, para ambos, sean innegociables. El primero es éste de la semejanza entre Dios y hombre. Hombre y Dios son, de alguna manera, trascendentes a la naturaleza: Dios lo es totalmente, pues la ha creado y ha decretado las leyes que rigen su funcionamiento. El hombre, en la medida en que posee una facultad en

9 Así es como se referirá, pasado un año de la publicación de La Doctrine curieuse ... a François Ogier, a quien acusa de ser un calvinista encubierto, autor de los Jugemens \& Censure du Livre de... François Garasse: «[...] ha aprendido, de las predicaciones de sus ministros, que los destinos lo hacen todo, y que nosotros no tenemos de qué preocuparnos, valiéndonos más dejarnos conducir, y gobernar nuestros asuntos, por el destino».

10 Apologie du père François Garassus..., pp. 240 - 241.

11 Cfr. La Doctrine curieuse ..., fol. 335: «[...] concluyo, y digo, que es hoy más peligroso que nunca remover esta cuestión del destino y de la predestinación fuera de las Escuelas de teología, pues los espíritus débiles y puntillosos hallarán en ella más motivo para perderse que materia para su edificación».

12 Cfr. ibid., fols. $388-389$. 
cuya virtud se muestra capaz de romper las leyes de la necesidad del «orden natural» al que el resto de la creación está sujeto:

[...] no hay nada visible en el mundo, excepto únicamente el hombre, que no actúe necesariamente, y únicamente el ser infinito puede dar este grado de libertad a la obra maestra de su potencia. Concluid, pues, que es necesariamente omnipotente ${ }^{13}$.

La libertad del albedrío, marca de la semejanza del hombre con su creador, lejos de ser incompatible con la potencia de Dios, constituye por sí sola una demostración de su omnipotencia. A partir de este punto comienza en el texto de Mersenne un trabajo de demolición, simultáneo, de la herejía calvinista y de la impiedad libertina. Afirmar una potencia en la creación -la voluntad- que, siendo criatura, es en cierto sentido autónoma -es decir, libre- respecto de las determinaciones del orden natural, y, sobre todo, de la omnipotencia divina, lejos de contradecir la afirmación de esta omnipotencia, la refuerza de la manera más contundente posible. El mínimo despliega este movimiento teórico en un ataque frontal al deísmo, determinando con cierta precisión el vínculo de procedencia que lo convierte en una teoría que se sigue necesariamente -en la conciencia de todos los apologistas católicos de estos años- de una reflexión sobre algunas tesis centrales de la Reforma. El argumento es complejo, y su resolución sitúa a ambas doctrinas -y, por extensión, al libertinismo en general- en el lugar que les corresponde: el exterior del espacio intelectual que definen la teología y la metafísica verdaderas. Esto es, católicas.

La primera parte de L'Impiété des Déistes es una larga refutación de una serie de cuartetos anticristianos, los 105 Quatrains du Déiste ${ }^{14}$, de autor desconocido, que compendian, de manera poco menos que sistemática, una doctrina acusada de albergar en su seno la forma más sibilina del ateísmo de los tiempos nuevos. Ha sido, precisamente, el calvinista suizo Pierre Viret quien la ha definido -y denunciado- en su Instruction Chréstienne en la Doctrine de la Foi et de l'Evangile (1564):

[...] he oído que hay [...] quienes se llaman deístas, con una palabra totalmente nueva que pretenden oponer a la de ateísta. Pues, así como ateísta significa aquel que es sin Dios, pretenden dar a entender que ellos no son, de ninguna manera, sin Dios, pues creen que hay algún Dios al que reconocen incluso como creador del cielo y de la tierra, como los turcos. Mas, de Jesucristo, no saben qué es, y no toman nada ni de él ni de su doctrina ${ }^{15}$.

Lo más expresivo del enrarecido y violento ambiente que se respira en estos años veinte del XVII, es el hecho de que Viret construye su definición acompañándola de una severa

13 L'Impiété des Déistes, I, 18, fol. 506.

14 Marin Mersenne parafrasea los 105 cuartetos en la primera parte de su escrito. Antoine Adam los ofrece íntegros, en su literalidad, en su ya citada antología Les libertins au XVIIe siècle (op. cit., pp. 90 - 108).

15 Pierre Viret, Instruction Chréstienne en la Doctrine de la Foi et de l'Evangile. Pierre Bayle reimprime la definición en su Dictionnaire historique et critique, en la entrada «Viret». De aquí tomamos el fragmento citado. Vid. Antony McKenna, Pierre Bayle, témoin et conscience de son temps. Un choix d'articles du Dictionnaire historique et critique, París, Honoré Champion, 2001. 
advertencia sobre el veneno oculto que entraña esta doctrina, y Mersenne, aun repitiendo la denuncia del calvinista casi en su literalidad, no se cansa de afirmar que el origen de esta nueva forma de impiedad se debe, sin ningún género de dudas, a la Reforma protestante y a su desacralización del cristianismo católico. Tal es la idea sobre la que insiste el mínimo en la dedicatoria a Richelieu de la primera parte de su obra ${ }^{16}$.

El historiador de las ideas, en efecto, percibe en la prosa de Mersenne el reflejo de las estrategias que la ofensiva católica está desplegando en su lucha por la hegemonía teológica y cultural en la Francia de la época. El mínimo, es obvio, debe ser muy consciente de que deísmo y protestantismo no son exactamente lo mismo. Una relación de procedencia no es nunca una relación de identidad. Para el deísta, a fin de cuentas, el cristianismo reformado construye también una representación de Dios que no puede ser considerada más que como una forma -otra más- de superstición. Es ésta, muy exactamente, la idea que estructura el escrito que nos ocupa: el deísta niega la verdad del cristianismo -de todo cristianismo, incluido, por supuesto, el reformado- porque percibe en él, como en toda religión no exclusivamente racional o natural, un antropomorfismo intelectualmente insostenible. Considera que muchos de los principios que vertebran la Reforma calvinista -la predestinación, y su concepción de la potencia de Dios como absoluta-conducen a un inaceptable cúmulo de contradicciones y de antinomias respecto de aquella representación cristiana de la divinidad, al que los propios reformados son incapaces de dar respuesta ${ }^{17}$.

La filiación, la genealogía, está siendo construida con cierta solidez ${ }^{18}$. El deísta señala las antinomias y contradicciones contenidas en una teología cuyos principios fundamentales implican un necesitarismo absoluto. El argumento es esencial, y complejo: el germen de la

16 L'Impiété des Déistes, I, «Dedicatoria»: «Este monstruo, hijo del caos y de la noche, ha vomitado desde hace unos años, bajo el nombre de ateísmo (el cual ni siquiera debería nombrarse entre los hombres), unas blasfemias contra Dios que han irritado al cielo contra nosotros, y que la tierra ha expiado mediante las llamas vengadoras de la ofensa a su Señor. Mas, como la soberbia carece de límites, y siempre crece, ha hecho renacer en nuestros días, de las cenizas de estos infelices, y en el corazón de nuestra Francia, otra secta que, bajo la trampa de un nombre más especioso, expone un veneno cuyo contagio es más pernicioso que el primero. Los cómplices de esta facción, Monseñor, toman el nombre y el título de deístas para engañar a las almas más simples y crédulas, haciéndolas creer que reconocen un Dios. Pero su designio, sin embargo, es minar silenciosamente las columnas y los fundamentos de la verdad católica».

17 Ibid., I, 26, fols. 823 - 824: «Que los calvinistas y los demás herejes se vean tan impedidos cuanto quieran para resistir a los deístas -a quienes he oído decir que aquéllos no pueden responderles- y delante de los cuales tiemblan, pues nosotros no tememos más a los unos que a los otros. En cuanto a mí, me parece que éstos no son sino vástagos de aquéllos, y a cualquier hereje que quiera discutir conmigo le mostraré que no tiene mejor derecho que el deísta, si es que quiere mantenerse en su herejía. He aquí a dónde conducen los reformadores el mundo; en lugar de hacer cristianos reformados, engendran deístas, ateos y libertinos».

18 Mersenne convocará el macabro espectro de algunos ateos y libertinos, gozosamente ejecutados ya para escarnio público, cuyo itinerario espiritual confirma sobradamente lo expuesto. Cfr. ibid., II, 16, fols. 279 - 280: «[...] si reflexionáis sobre sus personas, creo que hallaréis, al final de vuestras cuentas, que son jóvenes aventados que, después de haber sido calvinistas, se convierten en ateos y libertinos, como Geoffroy de la Vallée, quemado en París en el año 1572 junto con su libro del arte de no creer en nada, y como Noël, ejecutado en Metz. Pues el primero decía que quien pretenda alcanzar la maestría en su escuela, y llegar sin dificultad al punto de la libertad que él enseñaba, tenía que leer los libros de Calvino, y que para ser buen ateo hay que estar versado en su doctrina. El segundo confesó que lo que le había llevado al ateísmo era el artículo reformado que hace de Dios autor de condenación, pues decía que habría preferido adorar a un Saturno que se comiera a sus hijos, a un Júpiter adúltero, a un Baco borrachuzo, a un Mercurio engañador, o, más bien, creer que no hay Dios, antes que creerle autor de la ruina del hombre y de la pérdida de los reprobados». 
mutación del calvinismo en que según la apologética católica consiste el deísmo, yace, muy precisamente, en la aceptación del necesitarismo que se sigue de la doctrina calvinista de la potencia absoluta de Dios -la cual ha desembocado en el principio de la predestinación-, pero acompañada de la crítica, de la negación, del rechazo más firme de la representación cristiana de la divinidad. Aceptación, pues, del necesitarismo, y negación de la representación cristiana de la personalidad de Dios. No otra es la esencia del deísmo según Mersenne.

Casi al final de su escrito, el mínimo da la clave de su lectura de la impiedad: es la sustitución de la idea cristiana de Dios por los conceptos de necesidad o de naturaleza, lo que se erige en enemigo teórico que es preciso destruir con todas las armas disponibles. El deísta, en el diálogo que finge Mersenne, termina por reconocer su error y por confesar las ocultas razones que lo han mantenido en él; como cabía esperar, el naturalismo que hasta entonces ha profesado este peculiar impío, no ha sido más que un manto bajo el cual ha disimulado su desenfreno pasional y su brutalidad. Pero esto no es aquí lo más relevante. Lo verdaderamente definitorio del concepto es la identificación automática que la conciencia católica establece entre libertinismo y toda doctrina que lo remita «todo a la naturaleza y a la necesidad»:

[...] yo deseaba vivir según mi pasión y mi brutalidad, sin estar sujeto a rendir cuentas de mis acciones. Es por esto por lo que me fingía un Dios, con todos los demás libertinos, que me parecía estar sentado en el cielo, o extendido por todas partes, pero que tampoco se cuidaba más de los buenos que de los malos; o, por hablar con más verdad, me esforzaba en referirlo todo a la naturaleza y a la necesidad, y en ahogar con igual cuidado y diligencia todas las buenas inspiraciones que golpeaban mi espíritu y que me invitaban a abandonar mis errores ${ }^{19}$. (cursivas mías)

Un año más tarde, Mersenne cerrará su última gran obra apologética, La Vérité des Sciences, con un pequeño intercambio entre sus personajes principales, el escéptico y el filósofo cristiano, que corrobora esta idea acerca de la esencia del concepto de libertinismo. Una vez convencido de la absoluta falta de solidez del escepticismo que hasta este momento ha dicho profesar, el interlocutor de Mersenne, haciendo un auténtico alarde de disciplinada aplicación en el aprendizaje de las lecciones dispensadas por el piadoso filósofo cristiano, compendia y define los principios que deben ser aceptados y defendidos hasta el final. Pese a lo que cabría esperar, quizás ingenuamente, tras la lectura de una refutación sostenida del pirronismo, lo que se muestra en este final del tratado como en verdad decisivo en las posiciones enfrentadas, es la total necesidad de pensar a Dios como ser soberano. Y, sobre todo, como soberanamente libre:

EL ESCÉPTICO. Me hacéis recordar una razón maravillosamente potente para probar que es necesario que haya un Dios, pues hay miles y miles de cosas que vemos, las cuales, no obstante, podrían ser de otra manera, pues su naturaleza no depende de este lugar, de este tiempo, de este orden que poseen, ya que ello es, a menudo, indiferente, $y$, así, es preciso, necesariamente, que haya un ser soberano libre que haya establecido este orden en el mundo que vemos.

19 Ibid., II, 11, fols. $236-237$. 
EL FILÓSOFO. Emprendéis un discurso que es muy elevado, pues, cuando se trata de Dios, es preciso hablar de él con honor, admiración y asombro, ya que nuestros entendimientos, aunque penetrantes y acerados, no pueden comprender los misterios de la divinidad. Sin embargo, vuestra consideración está muy bien traída, pues es cierto que no podríamos rendir ninguna razón de muchos efectos, si no recurriésemos a una primera y soberana causa de la cual dependan todas las cosas, y que no dependa de nadie ${ }^{20}$.

La única necesidad aceptable es la que lleva a reconocer, a postular, la existencia de un ser soberano y soberanamente libre; esto es, no determinado por necesidad alguna, por nada que no sea su libre y propia voluntad.

Así pues, la mayor impiedad, aquella que constituye el primer principio del libertino tal y como su concepto es forjado por la apologética cristiana, católica como protestante, y de cuya aceptación se siguen todas las formas que haya podido adoptar, o bajo las cuales haya podido ser denunciado, no es sino la negación de la idea de libertad del albedrío. Es esto lo considerado como ateísmo en este período de la historia intelectual europea; el necesitarismo quintaesencia lo más esencial del libertinismo. Un necesitarismo que también ha avanzado oculto a la mirada de los historiadores de la filosofía del XVII, debido tal vez al cegador resplandor con que ha brillado la metafísica de Descartes, eminente teórico de esa idea de la libertad, y de los conceptos vinculados a ella. Es decir, maestro forjador del espacio intelectual moderno a que antes aludía.

Reforma, deísmo, nuevo epicureísmo... Decía antes que todo compone la misma pesadilla para Mersenne. La que se teje con los diamantinos hilos de la necesidad. Lo único impostergable es la destrucción de toda concepción de Dios que no deje lugar a su libertad, ni a la consiguiente libertad del albedrío de los hombres. La funesta síntesis de naturaleza y necesidad es, sin duda, una muy perfecta encarnación del mal. La crítica mersenniana nos permite percibir entonces, con mucha claridad, la forma más acabada y profunda de aquel espacio intelectual. Esto es, las consecuencias que acarrea la exigencia de pensar a hombre y Dios como soberanamente libres.

En primer lugar, es preciso reconocer que hay un límite cuya transgresión extravía irreparable y automáticamente a quien pretende forjarse una representación adecuada de la naturaleza divina. Se debe respetar un cierto margen de arracionalidad - un punto ciego para la capacidad natural del hombre- en la reflexión sobre la naturaleza de Dios. Sólo asumiendo este margen se hace posible escapar del grave peligro que conlleva pensar lo absoluto como sometido, de un modo u otro, a lo que no es absoluto. Ese margen no es sino una libertad pensada como refractaria, por su propia esencia, a todo tipo de sujeción, de necesidad, de determinación. Sólo pensándola como propiedad eminente de Dios, como perfección divina, se hace posible la ruptura del infernal círculo de la impiedad. La aniquilación, por tanto, de toda forma de libertinismo.

Mersenne resuelve su refutación del deísmo ocupándose de la metafísica de Giordano Bruno. La tesis del nolano en la que se sustancia su magisterio sobre el libertinismo es aquella según la cual es racionalmente necesario que Dios, puesto que es infinito, haya creado un

20 La Vérité des Sciences, IV, 15, fols. 919 - 920. 
mundo igualmente infinito. Ahora bien, lo realmente impío no es la afirmación de la infinitud del mundo; el mínimo, según él mismo escribe, es capaz de aceptar la compatibilidad de su Dios con una creación infinita ${ }^{21}$. Lo verdaderamente ateísta es afirmarlo sosteniendo que Dios habría operado su creación constreñido por su propia infinitud; lo inaceptable, por tanto, es sostener que Dios se habría visto necesitado a crear el mundo dotándolo de determinadas características o propiedades. La operación en verdad impía es la consistente en someter a Dios a una necesidad que refleja el encadenamiento que traba los términos de una deducción: si Dios es infinito en su esencia, en su potencia, en su voluntad, entonces su creación debe ser necesariamente infinita. La tesis que se ha de afirmar es la contraria: siendo una perfección, la libertad -la no sujeción a ningún tipo de necesidad; la indiferencia- no puede dejar de ser una propiedad de Dios, de manera que negarla, afirmando que está sometido en su acción a alguna necesidad, a cualquier especie de necesidad, es negar que su naturaleza sea realmente divina. Ateísmo significa aquí pensar a Dios como ligado, en su esencia, a la creación. Es decir, como principio inmanente a la naturaleza misma:

[Bruno] trata de probar que Dios carece de libertad, a fin de persuadir sus mundos infinitos. Mas lo intenta en vano, pues la libertad no sería una perfección si no se diese en Dios. Le preguntaría gustosamente, a él o a sus seguidores, si Dios no ha podido hacer esta tierra sobre la que caminamos más ancha o más pequeña, si no ha podido alejarla más del sol. Creo que no hay hombre en la tierra que no me conceda que Dios podría haber hecho una tierra cien veces más pequeña, o más grande, que habría podido emplazar el sol donde están las estrellas, y que podría haber hecho mil cosas que no ha querido hacer. De lo contrario, habríamos de decir que Dios está hasta tal punto ligado a esta tierra, y su infinitud ligada hasta tal punto a las cosas que son finitas, que no puede ser omnipotente e infinito sin ellas, lo cual no puede ser ni ser concebido de ninguna de las maneras ${ }^{22}$.

Libertad de elección, por tanto. Dios ha elegido dotar a su creación de unas propiedades, pero no de otras, sin que nada haya podido determinar sus decisiones. Ni siquiera la infinitud de su propia naturaleza. Una representación adecuada de la omnipotencia de Dios exige la asunción de su propia determinación, de su propia autolimitación. Sólo la afirmación de la libertad de Dios - de su libertad de elección y rechazo- ofrece una salida a las paradojas, antinomias e impiedades en que han caído reformados y deístas. Y también Bruno, aunque haya construido un complejo sistema filosófico y científico.

En segundo lugar, y en cuanto al hombre, sola criatura eminentemente semejante a Dios, lo realmente significativo es que su libertad constitutiva, la fuerza que define lo más específico de su naturaleza excepcional, lejos de mermar o de limitar la omnipotencia divina, la confirma. Incluso el mal uso de nuestra libertad, escribirá Mersenne un poco más adelante,

21 A pesar de que en este momento de su biografía intelectual se declare explícitamente seguidor de la física de Tycho Brahe, y afirme no creer en la verdad de las afirmaciones de Kepler y Copérnico, Mersenne es capaz de sopesar abiertamente la posibilidad de que el universo sea realmente infinito. Véase L'Impiété des Déistes, II, 17 , fols. $324-325$.

22 Ibid., I, 10, fols. $231-232$. 
revierte en la gloria de Dios. La cita es larga, pero en ella se talla el núcleo más irreductible de la posición católica antilibertina y anticalvinista:

[...] el concurso de Dios, por el que realiza la misma acción que hacemos nosotros, está bien ordenado, y sigue el decreto divino de su santa voluntad, pues Dios presta su ayuda al pecador por el amor que se tiene a sí mismo, dado que este concurso divino con nuestro liberal arbitrio se remite a la gloria de Dios como al último fin de todos los seres. ¿Acaso no es algo que conspira a la gloria de Dios, ver que ni siquiera podríamos jactarnos o glorificarnos de haberle ofendido, si, primeramente, no nos hubiera concedido la fuerza y la libertad para hacerlo? ¿No es esto algo que muestra la potencia de Dios: que, a pesar de que abusemos de su potencia, sabe extraer de ello honor y gloria, y que no hay maldad alguna que pueda sobrepasar su bondad y justicia?

Lo que os digo acerca del concurso divino, hay que entenderlo también del decreto eterno por el que Dios ha querido permitir que el hombre elija el mal, de suerte que, no obstante, le da la fuerza y la habilidad para seguir antes el bien que el mal, si quiere hacerlo [...] Dios no quiere, de manera absoluta, impedirnos hacer lo que queramos, sino que quiere que usemos plenamente de nuestra libertad, la cual, aunque él no la haya ordenado, o podido ordenar y referir al mal, sin embargo, no ha querido impedir que se remitiese a él [al mal] y que lo eligiese, si es que quiere hacerse esclava del pecado. Esta potencia que posee de poder pecar, procede de la parte de su no ser, en tanto que no es por sí misma, pues Dios no nos ha dado esta potencia para ofender, ni siquiera en tanto que se refiere al pecado...23

A continuación dará la que quizás es la clave mayor de la idea de libertad que está en juego... y que atravesará, como un principio incuestionado e incuestionable, la gran metafísica del XVII. En función de ella, los límites de la razón natural del hombre quedarán como velados. Mersenne los asume, $\mathrm{y}$, asumiéndolos, considera que puede ofrecer una explicación satisfactoria de aquello que el entendimiento no alcanza, no puede alcanzar, a comprender.

La voluntad de Dios queda convertida -tal es la tercera consecuencia que conlleva pensar a hombre y Dios como soberanamente libres- en una suerte de último refugio para los verdaderos espíritus fuertes, como un verdadero asilo de la sabiduría. La subversión del criterio con que los propios libertinos se definían a sí mismos, desmarcándose por completo de los llamados espíritus débiles, es ya total:

[...] es falta de espíritu, y de juicio, preguntar por qué Dios ha hecho el mundo con el orden que en él observamos a cada momento, pues posee una voluntad infinita, la cual es la regla soberana de todo lo que lo que es y de todo lo que puede ser bueno y bello.

Es por esto por lo que es preciso creer que ha tenido razón al elegir este mundo, tal y como es, entre una infinidad de millones que habría podido hacer en lugar de éste, aun cuando no sepamos por qué [...]

23 Ibid., I, 17, fols. 485 - 487. 
Quien posea un buen espíritu se resolverá muy pronto acerca de tales pensamientos, pues, meditando por qué Dios no hace una infinidad de cosas que podría hacer, tendrá inmediatamente, con el profeta real [Salomón], su recurso a la voluntad de Dios, omnia quacumque voluit, fecit, y no ha hecho nada de lo que no ha querido hacer. He aquí el destino de un juicio bien hecho, el cual adorará siempre con una profunda humildad el orden y la manera como Dios se comporta en todas sus obras ${ }^{24}$.

La libertad se revela, finalmente, como un postulado, pues es tan rigurosamente incomprensible como toda suspensión de la necesidad natural. Y aquello que encarna de manera estrictamente rigurosa dicha necesidad -la razón, el entendimiento- se muestra, a los ojos del católico, como incapaz de penetrar lo más digno de reverencia: la naturaleza de Dios. La libertad de la voluntad, la semejanza de hombre y Dios, es el nombre del misterio. Constituye el margen de arracionalidad que es del todo preciso preservar.

Así pues, y en resumen, el hombre, única criatura cuya acción puede poseer calidad moral por brotar de un albedrío libre, es capaz de hurtarse a las férreas cadenas de la necesidad natural a que se haya sometido todo lo que es. Único ser creado a imagen y semejanza de su creador, su existencia no transcurre necesariamente bajo el yugo de las leyes que conforman el reino de la naturaleza. Sola criatura inmortal y libre, posee un imperio -una voluntad, una potencia positiva- propio, distinto del natural. Dicho con una fórmula célebre: el hombre es un imperio dentro de otro imperio. Una gran cantidad de las páginas que el mínimo ha publicado en contra de los libertinos, ha sido escrita para consolidar esta idea.

En la segunda parte de L'Impiété des Déistes, lo hará afirmando que la única demostración de la excepcionalidad de esta criatura -su inmortalidad, su libertad-, de esta especie de infinitud que «en cierta manera» comparte con Dios, es la sensación que todo hombre experimenta por el hecho de ser hombre. El margen de arracionalidad que, como decía antes, es preciso reconocer para poder forjar una representación adecuada de Dios, se desliza en el discurso cuando de lo que se trata es de pensar la peculiar esencia del hombre, tan racionalmente incomprensible como todo lo que escapa a las muy racionales leyes de la necesidad causal que opera en la naturaleza. No cabe aquí demostración alguna, concatenación necesaria de argumentos. Sólo hay lugar para la constatación; el hombre siente su inmortalidad, así como su libertad. Y ello es testimonio, razón y autoridad suficientes - escribe Mersenne- para tener la certeza de su verdad ${ }^{25}$.

El hombre, así pues, vive en la naturaleza, rodeado de criaturas que carecen de libertad, como en una suerte de exilio. Sensación de inmortalidad, experiencia, sobre todo, de la libertad... Todo lo verdaderamente esencial indica de la manera más clara que el hombre no es una mera parte de la naturaleza. Es, literal y efectivamente, un imperio dentro de otro imperio. Es éste el punto verdaderamente intocable, el que establece la diferencia esencial, la particularidad de una esencia que hace del alma una suerte de cera blanda en la que ha sido sellada la imagen y la semejanza de su creador:

24 Ibid., I, 18, fols. $518-521$.

25 Cfr. ibid., II, 4, p. 515: «[...] la inmortalidad del alma racional, que no precisa de otro testimonio, ni de otra autoridad o razón más que de ella misma para para aprehender y sentir su inmortalidad...». 
[...] quienes no encierran nuestras almas en la consideración del espíritu del mundo, y confiesan, con los cristianos, que hay tantas almas infusas como hombres sobre la tierra, todas las cuales son diferentes y han sido creadas por Dios cuando el cuerpo del hombre está perfectamente organizado, éstos, digo, no son herejes, pues la Iglesia católica nada ha determinado acerca de la incorruptibilidad de la forma y del alma de todas las cosas sublunares. Es por esto por lo que no se ha de acusar de herejía formal a la opinión de aquellos que sostienen que todos los cuerpos del universo poseen una misma forma, al igual que una misma materia (excepto el cuerpo del hombre, en el que Dios ha puesto una forma que porta su imagen y su semejanza), tanto porque se someten al juicio y a la corrección de la Iglesia y de la teología, como porque explican su opinión conformemente a lo que es de nuestra creencia y a lo que se ve por experiencia ${ }^{26}$. (cursivas mías)

Mersenne pone a punto de esta manera un principio con el que rechazar categóricamente toda tentativa de restringir o de negar la responsabilidad moral de los actos humanos. Es decir, un principio que torna del todo imposible negar la trascendencia de Dios respecto de la naturaleza y los hombres. La voluntad humana no es la voluntad de Dios; no es expresión suya; nuestros actos, posean la calidad que posean, no cumplen deseo divino alguno. Este principio brinda al mínimo las condiciones necesarias para desplegar un argumento muy decisivo en su combate contra la crítica libertina de la objetividad de la moral. Mersenne puede afirmar fundadamente la imposibilidad de negar la sustancialidad del sujeto de la acción moral, pues se trata de un sujeto libre en sentido total:

[...] verdaderamente no sé lo que debo pensar de estos libertinos, pues la Naturaleza (a la que llaman su dulce madre, su dueña, su reina, su diosa y su todo, porque siguen su inclinación y se convierten en esclavos voluntarios de todos sus movimientos, por desordenados que sean) no les conduce al alma del Universo: sienten en sí mismos, todos los días, miles y miles de movimientos particulares que no pueden nacer más que de una naturaleza particular ${ }^{27}$. (cursivas mías)

Lo decisivo, por tanto, es la afirmación de la trascendencia del principio de todo lo que es respecto de todo lo que de él depende, incluido lo que más se le asemeja, junto con la afirmación del carácter sustancial de eso que más se le asemeja por ser igualmente libre en su esencia. Todo subterfugio pergeñado para entregarse -alegremente o no- a la asunción de la necesidad -sea natural, o presente un carácter puramente escatológico- está siendo cuidadosamente liquidado. Ciertamente, nos hallamos ante un punto esencial de la apologética cristiana moderna.

Así pues, no hay necesidad que pueda desvanecer, como si de un sueño se tratase, la responsabilidad moral que se atribuye a las acciones de los hombres. La divinidad, contrariamente a lo que han sostenido muchos naturalistas en el pasado reciente -Giordano Bruno, por supuesto, pero también Vanini, a cuyo escrito más afamado, De admirandis Naturce

26 Ibid., II, 27, fols. 479-480.

27 Ibid., II, 23, p. 640.

Daimon. Revista Internacional de Filosofía, nº 69, 2016 
Regince Deaque mortalium arcanis libri quator, publicado en $1616^{28}$, hace Mersenne alusión velada en el pasaje que acabo de citar- es necesariamente trascendente:

[...] no veo cómo la sola concurrencia de los accidentes corporales que hacen nuestro cuerpo pueda ser causa de la libertad que sentimos en nosotros mismos, dado que la libertad no depende de las cosas corpóreas, como se muestra en las acciones libres, que se elevan por encima de la materia y se separan de toda suerte de consideraciones corporales, [si esto no fuese así] sería preciso, necesariamente, que nuestra libertad dependiese de ellos y procediese de esa alma universal, a la que habría que atribuir todas nuestras acciones, puesto que ella sería su causa ${ }^{29}$. (cursivas mías)

La constatación de la libertad, junto con la correlativa constatación de la existencia individual de «un alma que es libre hasta tal punto que puede querer o no querer, odiar o amar, abstenerse de querer, y no querer todo lo que le plazca o le disguste ${ }^{30}$, es la prueba de que Dios, el hombre y la naturaleza son tan recíprocamente trascendentes como deben serlo creador, la más eminente de sus criaturas y el resto de las cosas creadas.

$* \quad * \quad *$

La apologética católica ha explicitado durante estos años las consecuencias implicadas en la exigencia de pensar a Dios y hombre como soberanamente libres. Así es como han sido establecidos los muy precisos límites dentro de los cuales va a evolucionar la filosofía más sistemática de la Modernidad. Trascendencia de Dios y naturaleza, sustancialidad irrenunciable del sujeto de la acción moral, concepción del hombre como una suerte de imperio de otro imperio en virtud de su libre albedrío, consideración de la voluntad de Dios como asilo de la sabiduría... El destino del libertino, el destino del extraño personaje que niega militantemente cada uno de esos principios, será el de una larga condena a permanecer confinado en las mazmorras más subterráneas de la historia. Pero el suyo no será un destino solitario. Arrastrará consigo a toda doctrina que se acerque, o que fundamente, sus principios. Cuando el siglo termine, en 1696, un protestante francés, extremadamente erudito, y exiliado en los Países Bajos -el Edicto de Nantes ya ha sido revocado-, escribirá un Diccionario histórico y crítico en el que repetirá, introduciendo algunos matices importantes, el principal gesto que los apologistas han dibujado cuando han tratado de exorcizar a la sociedad francesa del espectro que la acosa: trazará la historia de una doctrina cuya sola mención suscita un horror muy parecido al que ha puesto en marcha la maquinaria punitiva cristiana -simbólica cuanto física- desde mediados del siglo XVI. El erudito que escribe fragmentariamente esta historia es Pierre Bayle; la espeluznada fascinación que le lleva a tomar la pluma y a trazar la genealogía de la impiedad, es similar a la padecida por Mersenne y Garasse; y el nombre que adopta ahora en la escritura del hugonote no es ya el de libertinismo, sino el de spino-

28 Sorprendentemente, las autoridades eclesiásticas de la Sorbona permiten su publicación. Aunque, dicho sea en descargo de tan execrable desliz, prohíben y ordenan la quema pública del escrito apenas un mes después de haber faltado tan gravemente a sus piadosas obligaciones.

29 Ibid., II, 25 , p. 654.

30 Ibid. 
zismo. El desplazamiento, la invisibilización final de todas estas teorías que, de una manera u otra, con mayor o menor profundidad teórica, niegan la libertad de la voluntad de hombre y Dios, la objetividad de las categorías de bien y de mal, o la trascendencia del principio de la naturaleza, se deberá, al menos en buena parte, a la fuerza con que la metafísica cartesiana ha ocupado -consolidando su estructura- el espacio intelectual de la Modernidad, absorbiendo durante al menos dos siglos la atención de quienes se han ocupado de hacer y transmitir la historia de la filosofía.

Pierre Bayle, sin embargo, constituye una muy peculiar excepción. Tiránicamente seducido por la filosofía spinozana, en la que percibe la culminación, sustanciada en sistema, del ateísmo y la impiedad -el francés no deja de ser un cartesiano a su manera-, insiste en la heterogeneidad esencial entre los sistemas de Descartes y Spinoza, señalando alarmado los «execrables errores», las torpes incongruencias y los «horribles absurdos» de que está trufado, según él, el sistema del judío. Sus tesis más radicales -afirma Bayle sin perder el aliento-, son las que más explícitamente se oponen a los principios que sostienen el sistema cartesiano, las más diametralmente opuestas a las coordenadas que organizan y ordenan aquel espacio intelectual de la primera Modernidad europea. Y para exorcizar la idea que obsesiona su escritura, Bayle expone en su Diccionario la percepción que le persigue cuando se enfrenta al pasado de la filosofía: una suerte de «panspinozismo» que se habría ido afirmando, de manera más o menos intermitente, a todo lo largo de ella. El exiliado de Rotterdam, así, compone una especie de «contra-historia» del pensamiento, una suerte de historia de la impiedad y el ateísmo, la cual culminaría en la obra de Spinoza, especialmente en su Ética. Las concomitancias con lo que durante la primera mitad del XVII es concebido como libertinismo son palmarias.

El autor del Diccionario histórico y crítico sostiene que las tesis que identifican Dios y naturaleza, que niegan la posibilidad del creacionismo, que rechazan la existencia de un libre arbitrio, o la objetividad de las categorías fundamentales de la moral; las tesis en cuya virtud se postula la indiferencia de los dioses -en caso de que existan- respecto de los avatares del mundo y de los hombres, etc., obedecen a una suerte de tentación que ha aparecido y desaparecido, recurrente e intermitentemente, a lo largo de la historia. Habría, afirma Pierre Bayle, una especie de «spinozismo histórico» que comparece ante la mirada del historiador atento, como si de una tentación eterna y maligna del espíritu se tratase, por ejemplo, en cierta tradición aristotélica, en el período helenístico -especialmente en la escuela de Epicuro-, a lo largo de la Edad Media, o, sobre todo, en el Renacimiento.

Pero Bayle es un historiador sutil: no identifica, sin más, este «panspinozismo histórico» con la filosofía de Spinoza; considera que el filósofo de Ámsterdam ha aplicado metódica, geométricamente su espíritu a unos principios tan eternos como el mal. La filosofía de Spinoza sería, por tanto, la sistematización de un «spinozismo» anterior y en cierto modo independiente del portador del nombre con que la doctrina es bautizada; sería la sistematización de una suerte de estructura del espíritu absolutamente execrable, extraña a todo vestigio de buen sentido y de humanidad. El filósofo, afirma Bayle de una manera que se perpetuará durante una buena cantidad de decenios, habría forjado en el fuego del infierno un sistema en el que ateísmo e impiedad -es decir, algo muy similar a eso que a principios de siglo es peyorativamente denominado como libertinismo- adquieren una solidez intelectual hasta entonces inaudita. Esta es la razón final de la alucinada fascinación del erudito Bayle. La 
metafísica de Spinoza sería la sistematización de gran parte de los principios que hemos visto organizarse, durante un período de tiempo muy concreto, en la obra del libertino. Y tal vez por ello la atención hacia este complejo movimiento intelectual haya sido despertada en el mismo momento en que lo ha hecho el interés historiográfico por la filosofía del judío de Ámsterdam...

Extraño concepto el de libertinismo... No sólo remite a un rechazo de la idea de libertad tal como es fundamentada en los inicios del siglo, sino que termina, pasados unos cuantos años, por encontrar savia nueva, por emerger como sistema, bajo la alargada y solitaria sombra del filósofo que ha alzado un sistema según el cual sólo puede atribuirse a la más profunda ignorancia la afirmación de aquella idea de la libertad cuya asunción será todavía durante siglos un auténtico criterio con el que dispensar filosóficas cartas de naturaleza. Ciertamente, la condena dictada sobre el spinozista será al menos tan dura como la que ha recaído sobre el libertino.

\section{Bibliografía}

Albiac, G., Sumisiones voluntarias. La invención del sujeto político, Madrid, Tecnos, 2011. Albiac, G., Blaise Pascal: La máquina de buscar a Dios, Madrid, Tecnos, 2014, pp. 17 - 63.

Caussin, P., La Cour Saincte, ou l'Institution chrestienne des Grands, Ruán, David Ferrand, 1624 , in- $8^{\circ}$.

Garasse, F., La Doctrine curieuse des Beaux esprits de ce temps, ou pretendus tels, París, S. Chappelet, 1623 , in- $4^{\circ}$.

Garasse, F. , Apologie du père François Garassus, de la Compagnie de Jesus, pour son Livre contre les Atheistes \& Libertins de nostre siècle. Et response aux Censures et Calomnies de l'Autheur Anonyme, París, S. Chappelet, 1624, in-12.

Garasse, F., Nouveau Jugement de ce qui a esté dict et escrit pour \& contre le livre de la Doctrine curieuse des beaux esprits de ce temps, \& c., París, Jacques Quesnel, 1625.

Guez de Balzac, J. L., Lettres, París, T. du Bray, 1624, in-8 ${ }^{\circ}$.

Jiménez Lozano, J., Retratos y naturalezas muertas, Madrid, Trotta, 2000.

Lomba, P., Márgenes de la modernidad. Libertinismo y filosofía en el siglo XVII, Madrid, Escolar y Mayo, 2014.

McKenna, A., Pierre Bayle, témoin et conscience de son temps. Un choix d'articles du Dictionnaire historique et critique, París, Honoré Champion, 2001.

Mersenne, M., Qucestiones celeberrimce in Genesim, cum accurata textus explicatione, París, S. Cramoisy, 1623, in-folio.

Mersenne, M., L'impieté des Deistes, Athees et Libertins de ce temps, combatuë et renversee de point en point par raisons tirees de la Philosophie et de la Theologie. Ensemble la refutation du Poëme des Deistes, París, P. Bilaine, 1624, 2 vols., in- $8^{\circ}$.

Mersenne, M., La Verité des Sciences. Contre les Septiques [sic] ou Pyrrhoniens, París, T. du Bray, 1625 , in- $8^{\circ}$.

Moreau, P. F., Spinoza, París, Seuil, 1975. 
